\title{
Helicobacter pylori Eradication Therapy: Current Availabilities
}

\author{
M. Gasparetto, M. Pescarin, and G. Guariso \\ Unit of Gastroenterology, Digestive Endoscopy, Hepatology and Care of The Child with Liver Transplantation, \\ Department of Pediatrics, University Hospital of Padova, Via Giustiniani 2, 35128 Padova, Italy
}

Correspondence should be addressed to G. Guariso, guariso@pediatria.unipd.it

Received 23 April 2012; Accepted 19 June 2012

Academic Editors: J.-P. Buts and H. Shimoda

Copyright (c) 2012 M. Gasparetto et al. This is an open access article distributed under the Creative Commons Attribution License, which permits unrestricted use, distribution, and reproduction in any medium, provided the original work is properly cited.

\begin{abstract}
Background. Though Helicobacter pylori (HP) infections have progressively declined throughout most of the industrialized countries, a gradual increase in failure of HP eradication treatments is observed. Aim. To critically review evidence on the efficacy of the therapeutic availabilities for HP eradication, as yet. Methods. A selection of Clinical Trials, Systematic Reviews and Metaanalyses within the time period 2010-2012, was performed through a Medline search. Previous references were included when basically supporting the first selection. Results. An increasing rise in HP resistance rates for antimicrobial agents is currently observed. Further causes of HP treatment failure include polymorphisms of the CYP 2C19, an increased body mass index (BMI), smoking, poor compliance and re-infections. Alternative recent approaches to standard triple therapy have been attempted to increase the eradication rate, including bismuth-containing quadruple therapy, non-bismuth containing quadruple therapy, sequential therapy and levofloxacin-containing regimens. Conclusions. The main current aims should be the maintenance of a high eradication rate $(>85 \%)$ of HP and the prevention of any increase in antimicrobial resistance. In the next future, the perspective of a tailored therapy could optimize eradication regimens within the different countries.
\end{abstract}

\section{Introduction}

Helicobacter pylori (HP) is an ubiquitous gram-negative bacterium. Its specific microbiological features allow its survival in the stomach and the colonisation of the antrum. $\mathrm{HP}$ expresses high levels of urease enzyme, producing NH3 and $\mathrm{CO}_{2}$ from the urea being present in the gastric juice [1]. This mechanism called acid acclimation regulates the cytoplasmic $\mathrm{pH}$ of the bacterium and guarantees the maintenance of a periplasmic $\mathrm{pH}$ near neutrality, despite the acidic environment [2]. Once HP has colonised the stomach, an immune response begins; as a result, normal acid secretion and gastric architecture are modified. Consequences are gastritis, peptic ulcer disease, functional dyspepsia, and cancer. HP was first identified in 1982 and by 1989 had been associated with gastric inflammation and ulcers in adults and children [3]. During the 1990s evidence emerged of its etiologic role in stomach cancers in adults. HP was classified in 1994 among the group I carcinogens by the International Agency for Research on Cancer [4]. There are also a lot of associations between HP and other extra intestinal diseases such as cardiovascular diseases, diabetes mellitus, lung diseases, hematologic diseases, neurological diseases, and glaucoma. Nevertheless, more studies are necessary to delineate the cause-effect relationship for any of these issues [5]. Helicobacter pylori infects approximately $50 \%$ of the adult population $[1,6]$ : only $20 \%$ of HP-infected people are symptomatic whereas $80 \%$ of them are symptom-free.

\section{Aim and Methods}

This paper is conceived to critically review evidence on the efficacy of the therapeutic availabilities for HP eradication, available as yet. A Medline search was performed indicating as keywords "Helicobacter," "Eradication Regimens," "Eradication Rate," "Epidemiology," "Drug Resistance." A selection of relevant English-language clinical trials, systematic reviews, and meta-analyses within the time period 20102012 was performed. Previous references were included when basically supporting the first selection. PubMed, Cochrane Library, Trip Database, and Ovid Medicine were used as referral databases. 
Jadad Scale (score 0 to 5) was used as a predetermined strategy of inclusion for clinical trials.

\section{Epidemiology of $\boldsymbol{H}$. pylori Infection}

Over recent decades, HP infections have progressively declined throughout most of the industrialized countries. HP still represents, by the way, a clinical issue among those people who were infected as children at a time when HP was endemic or among immigrants coming from endemic countries $[14,15]$. Many different factors play a role in the development of HP infection, including geography, ethnicity, age, and socioeconomic elements [15]. The progressive decline in infection rates has been secondary to the improvements in sanitation as well as to the use of combination of anti-HP regimens over the past decades.

At the same time, a gradual increase in failure of $\mathrm{HP}$ eradication treatments is found [16] and the task of treating HP has now become increasingly challenging: a fall in the eradication success with standard triple therapy from over $90 \%$ in the 1990 s to $<60 \%$ is observed nowadays [17]. The main reason for eradication failures is antimicrobial resistance, in particular clarithromycin (CAM) resistance relates to a reduction in the success of standard triple therapies by $35-60 \%$ [18].

\section{Helicobacter pylori: Drug Resistance}

Since resistance rates for antimicrobial agents rise with their indiscriminate use, clarithromycin (CAM) resistance may be due to the widespread use of this agent for upper respiratory tract infections [19, 20]. De Francesco et al. showed [21] that HP antibiotic resistance rates all over the world are $17.2 \%$ for CAM, $26.7 \%$ for metronidazole (MNZ), $11.2 \%$ for amoxicillin, and $16.2 \%$ for levofloxacin. It is known that bacteria can develop efflux channels for CAM, which rapidly transfer the drug out of the bacterial cell, preventing the binding of the antibiotic to the ribosome [22]. It has been speculated that the disruption of the cell wall caused by amoxicillin prevents the development of efflux channels by damaging the wall of the bacterium, thus improving the efficacy of CAM in a second phase of treatment [23]. It has, however, to be taken into consideration that the improved effect with sequential and concomitant therapies compared with standard therapy may also be due to the larger number of antibiotics than to the sequential administration itself [24]. Since one meta-analysis reported an almost 60\% decline in eradication rates with standard triple therapy if CAM resistance was present [25], the use of standard triple therapy has been recommended only in those areas where CAM resistance is lower than $15-20 \%$. As a general rule, clinicians should prescribe therapeutic regimens that have a $\geq 90 \%$ efficacy [26]. There are several reasons causing treatment failure, the antimicrobial resistance being the most important; other lower causes are polymorphisms of the CYP 2C19, an increased body mass index (BMI), smoking, poor compliance, and reinfections [8, 27-29]. Since all the different HP therapies are long and complicated, a poor compliance is often found as the real reason of a treatment failure, particularly in the developed countries. New strategies to improve compliance should therefore be applied [30].

The prevalence of antimicrobial resistance might be significantly different between countries, which will greatly affect eradication rates $[1,31]$. For example, a significant increasing rate of resistance to CAM and MNZ in some parts of Asia including Japan [32] determines a reduced efficacy of PPI-based triple therapy. Cases of Nitroimidazole resistance as well as dual resistance (to both CAM and MNZ) are described [33]. For these latter patients, concomitant therapy may be more suitable than sequential therapy. The increase in MNZ resistance appears, however, less important with respect to CAM, as a dose increase and a longer treatment period consent to avoid HP infection. Given the described geographical variability, the development of better treatments for HP infection should take into consideration the distribution of antibiotic resistance among affected populations in different geographical areas; however, these data are still lacking outside the USA. A recent meta-analysis of five randomized controlled trials totalling 701 patients [34] showed that culture-guided triple therapy is superior to standard triple therapy referring to a higher eradication rate from intention-to-treat analyses (CI 0.77-0.9, $P<0.00001$ ) and a lower overall cost. Antimicrobial susceptibility testing is therefore recommended before first-line treatment for HP infection. Another important factor is polymorphism of the CYP2C19 isoenzyme $[35,36]$ that is responsible for the biotransformation of several PPIs: significant differences in eradication rates have been observed between homozygous and heterozygous extensive metabolizers and poor metabolizers of PPIs (omeprazole being the most affected, followed by lansoprazole). As a consequence, the use of higher doses may be required. Orientals, for instance, are low metabolizers than Caucasians. The influence of age on the efficacy of concomitant treatment is unclear; the only study that has evaluated concomitant therapy in children showed favorable results (94\% of eradications in 33 children) [37]. Gender was not found to be a significantly predictive factor for success or failure of HP eradication in patients treated with concomitant therapy [38]. The main current effort should be to maintain the eradication rate of HP above $85 \%$ and to prevent any increase in antimicrobial resistance in the general population.

The possibility of a tailored therapy will be a chance in the next future to optimize the most effective eradication regimen within the various geographical areas; for this proposal, the determination of HP genotype from gastric tissue samples or stools as well as the determination of CYP2C19 polymorphism is required [39].

\section{Therapeutic Approaches Attempted for Eradication of $\boldsymbol{H}$. pylori}

The most widely recommended treatment in international guidelines for the eradication of HP is the Standard Triple Therapy based on a proton-pump-inhibitor (PPI) to which 
TABLE 1: Summary of the main current first- and second-line treatment regimens available for HP eradication.

\begin{tabular}{|c|c|c|}
\hline \multicolumn{3}{|c|}{ First-line treatment regimens } \\
\hline Triple standard therapy & $\mathrm{PPI}+\mathrm{CAM}+\mathrm{AMPC}$ and/or MNZ & $\begin{array}{l}\text { Eradication of HP infection from } 90 \% \text { to } 70-80 \% \\
\text { Steadily decline in treatment efficacy in USA [7] }\end{array}$ \\
\hline Sequential therapy & $\begin{array}{l}\text { PPI + AMPC for } 5 \text { days, then PPI + CAM } \\
+ \text { MNZ for other } 5 \text { days }\end{array}$ & Eradication rates of $90 \%-94 \%[8,9]$ \\
\hline Concomitant therapy & $\begin{array}{l}\text { PPI + CAM + AMPC + MNZ for 7-10 } \\
\text { days }\end{array}$ & $\begin{array}{l}\text { Eradication rate of } 90 \% \text {. More simple regimen, good } \\
\text { alternative to standard triple therapy }[10]\end{array}$ \\
\hline $\begin{array}{l}\text { Bismuth-based quadruple } \\
\text { therapy }\end{array}$ & $\begin{array}{l}\text { PPI }+ \text { Bismuth }+ \text { Tetracycline }+ \text { MNZ for } \\
\text { 10-14 days }\end{array}$ & $\begin{array}{l}\text { Important role in countries with high CAM resistance } \\
\text { rate; in a recent study patients took PPI and a } \\
\text { three-in-one capsule containing bismuth subcitrate } \\
\text { potassium, MNZ and Tetracycline with eradication } \\
\text { rates of } 80 \% \text { versus } 55 \% \text { in the standard therapy group } \\
\text { [11] }\end{array}$ \\
\hline \multicolumn{3}{|c|}{ Second-line treatment regimens } \\
\hline Levofloxacin-based triple therapy & PPI, levofloxacin, and AMPC & $\begin{array}{l}\text { Good alternative for patients who failed with standard } \\
\text { treatment. A recent meta-analysis highlighted that } \\
\text { levofloxacin-based triple therapy has lower incidence in } \\
\text { side effects than the bismuth-based quadruple therapy, } \\
\text { as well as a better eradication rate ( } 87 \% \text { versus } 68 \%) \\
{[12]}\end{array}$ \\
\hline $\begin{array}{l}\text { Rifabutin-containing rescue } \\
\text { therapy }\end{array}$ & & $\begin{array}{l}\text { Well tolerated, good alternative for patients who failed } \\
\text { with a first-line therapy [13] }\end{array}$ \\
\hline
\end{tabular}

AMPC: amoxicillin, MNZ: metronidazole, CAM: clarithromycin, and PPI: proton pump inhibitor.

two antibiotics (CAM plus amoxicillin (AMPC or MNZ) are associated for 7 days [37-41]. With few exceptions, the standard triple therapy now provides unacceptably low treatment success (i.e., $80 \%$ or less) [42]: two recent double-blind multicentre studies have evidenced low eradication rates with standard therapy $(77 \%)[43,44]$ and two meta-analyses on more than 53.000 patients have confirmed this data $[45,46]$. As a consequence, new alternative recent approaches have recently been attempted to increase the intention-to-treat (ITT) eradication rate, possibly over $85 \%$ (Table 1) [47]. For many years, a recommended alternative approach (Maastricht III Consensus and Guidelines of American College of Gastroenterology) has been the addition of PPIs to the old regimen comprising a bismuth salt, tetracycline, and MNZ [48]. A meta-analysis on triple versus bismuth-containing quadruple Therapy for HP infection demonstrated that $80 \%$ of patients who received quadruple therapy and $79 \%$ of patients who received triple therapy achieved eradication by ITT analysis, indicating a similar effectiveness for the two regimens, even though bismuth-based quadruple therapy is known to be useful after failure of PPI-based triple therapies (average eradication rate of $76 \%$ for quadruple therapy when used as second-line therapy) $[49,50]$.

An efficacy of ranitidine bismuth-based triple therapies has also been demonstrated as retreatments [51]. Nonbismuth quadruple therapy (PPI-CAM-AMPC-nitroimidazole) also represents a safe alternative to triple therapy and should be taken into consideration when the efficacy of triple therapy results in being unacceptably low [33]. A review article by Gisbert et al. [52] critically evaluated the evidence existing on the role of non-bismuth quadruple therapy (PPI-clarithromycin-amoxicillin-nitroimidazole) [53-55] in the treatment of HP infection. This regimen appears to be effective, safe, and suited for use in settings where the efficacy of triple therapy is unacceptably low.

Because of the scarce compliance to these regimens as well as the increased resistance to both CAM and MNZ, the "sequential therapy" was introduced as a promising new treatment comprising 5 days of amoxicillin with a PPI, followed by 5 days of the same PPI but with a nitroimidazole (tinidazole, MNZ) together with CAM. The sequential therapy was largely experimented in Italy where an increase in the eradication rate by at least $10 \%$ was observed, compared with standard regimens, independently on clarithromycin resistance $[56,57]$. This regimen has been demonstrated more effective than standard triple therapy by several clinical trials and meta-analyses $[58,59]$. By the way, sequential therapy has not been subjected to any clinical trial in the United States, yet. A recent trial in South America, demonstrated the standard 14-day triple therapy to be more efficacious than the 10-day sequential four-drug regimen [60]. A study by Hsu et al. on a cohort of patients in Taiwan, compared an extended 14-day therapy to the 10-day sequential therapy, without attesting any improvement [61]. A study by Miehlke et al. showed that a high-dose PPI dual therapy with AMPC was effective as a salvage treatment for eradication of $H$. pylori resistant to both CAM and MNZ, with an ITT of 76\% [62]. A study by Attumi and Graham evaluated the efficacy of a prolonged dual therapy (AMPC and omeprazole for 6 weeks) without attesting any improvement in treatment outcome (ITT of 63\%)[63], thus suggesting that extending the duration of a dual therapy to more than 14 days is not effective for achieving an improved treatment outcome [47]. What finally emerges from this study is that higher doses 
and more effective agents represent a stronger approach for HP eradication than the simply longer duration [47]. The nonbismuth quadruple therapy and the sequential regimens resulted in being similar in terms of efficacy and safety. Several randomised controlled trials and meta-analyses have demonstrated that non-bismuth quadruple therapy is more effective and equally well tolerated as standard triple therapy. A meta-analysis of 15 studies showed a mean cure rate of $90 \%$ for non-bismuth quadruple therapy. CAM resistance may reduce the efficacy of non-bismuth quadruple therapy, although the eradication rate remains much higher than in standard triple therapy. Many studies have included Levofloxacin and shown good eradication rates, indicating a levofloxacin-based triple therapy as another option for patients with persistent infections [64].

In a recent trial by Basu et al. [65] a new regimen with high eradication rate was proposed: a novel drug combination was tested within a clinical trial and compared with a standard triple therapy (amoxicillin, CAM, and lansoprazole). This new regimen was called LOAD as it comprised three antibiotics (levofloxacin, doxycycline, and nitazoxanide, a prodrug with antiparasitic properties) together with omeprazole; its efficacy was supported by an eradication rate of $90 \%$ compared with $73 \%$ with the triple therapy. This relatively expensive novel drug combination would represent an absolute increase of $17 \%$ in the eradication rate (with a needed to treat number of 5.88 to achieve one more successful eradication). A concrete advantage of this regimen is the exclusion of any penicillin-based antibiotic, so that in those patients a real or perceived allergy to penicillin can be treated as well [7]. To be noticed as a limitation in the application of this regimen is the fluoroquinolone levofloxacin included in the treatment, which appears to rapidly generate resistance, with a peculiar increase recently demonstrated among Asian populations [9]. The elevated cost of nitazoxanide is also a socioeconomically issue to be take into consideration as regards the compliance to this new regimen proposed [7]. In Asia, the currently recommended first-line therapy for $H$. pylori infection is a PPI, AMPC, and CAM for 7 days [49]. According to the Maastricht III consensus, in naïve HP-infected patients, triple therapy using a PPI with CAM and AMPC or MNZ remains the recommended first-choice treatment [10]. Some authors have demonstrated the importance of $H$. pylori CagA status for the efficacy of antibiotic treatment considering an infection with cytotoxic strains as a good predictive marker of successful therapy $[11-13,66]$. A useful role for some probiotics including $S$. boulardii and $L$. reuteri as an adjunct to HP eradication treatment has recently been established $[67,68]$.

\section{Managing HP Infection in Children: The 2011 ESPGHAN and NASPGHAN Guidelines}

In 2011 the European and North American Societies of Pediatric Gastroenterology Hepatology and Nutrition (ESPGHAN and NASPGHAN) emitted evidence-based guidelines for managing HP in children [69]. These guidelines suggest to assess not only the presence of the HP infection but also all the other possible underlying causes of the specific clinical features. They recommend to test children having first-degree relatives with gastric cancer as well as children showing refractory iron-deficiency anemia with previous negative tests for other causes. Instead, screening for HP is not recommended in children with suspect of functional abdominal pain. HP positive peptic ulcer disease (PUD) is recommended for treatment. However, for children with HP infection without PUD, treatment should be considered by the clinician evaluating the potential advantages and the risk factors of a developed chronic infection with bad consequences. In children, the first-line recommended therapies are

(1) standard triple therapy with PPI (1-2 mg/kg/day), AMPC (50 mg/kg/day), CAM (20 mg/kg/day), or MNZ (20 mg/kg/day);

(2) bismuth-based quadruple therapy: bismuth subsalicylate $(8 \mathrm{mg} / \mathrm{kg} /$ day $)$, AMPC $(50 \mathrm{mg} / \mathrm{kg} /$ day $)$, and MNZ (20 mg/kg/day);

(3) sequential therapy: PPI (1-2 mg/kg/day) AMPC ( $50 \mathrm{mg} / \mathrm{kg} /$ day) for 5 days, then PPI (1-2 mg/kg/day), CAM (20 mg/kg/day), and MNZ (20 mg/kg/day) for 5 days.

As for adults, an antibiotic susceptibility test should be performed whenever a high resistance rate $(>20 \%)$ in the area is known. Once treatment is completed a non invasive test should be done to ensure eradication [69].

\section{H. pylori Infection and Diseases of the Upper Gastrointestinal Tract}

Over the past two decades, HP has represented a pivotal role in nonmalignant diseases of the upper gastrointestinal tract, as peptic ulcer disease (PUD), functional dyspepsia (FD), and gastroesophageal reflux disease (GERD) [70]. Irrespective of etiology, both incidence and prevalence of uncomplicated PUD have dramatically decreased in the developed countries in the last decades. By the way, rates of both ulcer complications and mortality still remain high nowadays. The prevalence of HP-associated ulcers is decreasing, whereas a role of nonsteroidal anti-inflammatory drugs (NSAID) is becoming predominant. In fact, in western countries a decline of HP prevalence is described as well as an increasing use of NSAIDs and aspirin, the latter mainly prescribed for cardiovascular protection [70]. As HPrelated PUD is the cause of symptoms in only a minority of patients with dyspepsia, recommendations on HP testing and subsequent eradication in all patients with dyspeptic symptoms vary greatly [71].

As regards FD (as defined by Rome III criteria) a possible role of HP still remains uncertain [69]. The pathophysiology of FD is actually multifactorial. Several randomized controlled trials performed in western countries and in Asia have given opposite results about the role of HP infection in causing FD, with no evidence for the former 
countries whereas a success of eradication has been obtained in some east Asian populations [70]. As HP may reduce gastric acid secretion, its colonisation has been reported to be inversely associated with the development of GERD [72]. HP infection would be protective towards gastroesophageal disease (GERD). By the way, HP is associated with esophageal squamous cell carcinoma, and long-term PPI treatments in patients with persistent HP infection may cause gastric atrophy, which is a precancerous lesion [72, 73]. It is reported that the widespread use of eradication therapy with a falling prevalence of HP infection has been paralleled with an increase in the occurrence of GERD [74]. By the way, other studies evaluating the same relation actually produced inconsistent results [75]. A systematic review by Qian et al. [76] was aimed to evaluate whether the eradication of HP would worsen or improve GERD, both from the clinical (heartburn, acid regurgitation) and endoscopical (erosive esophagitis) point of view. The 11 articles included in this met-analysis showed no significant difference between patients with HP eradicated and those with persistent infection. The authors therefore concluded that HP eradication does not worsen the clinical outcomes of GERD. Gastric cancer remains a major cause of cancer death worldwide [77]. Its pathogenesis is multifactorial and involves bacterial, host, and environmental factors that interplay in the histological progression to neoplasia. HP has been recognized as a major factor in the early stages of cancer development, so its screening and eradication are mandatory for cancer prevention. Population-based screening represents the current best option for the primary prevention of gastric cancer, the incidence of which largely depends on differences in HP CagA status and dietary factors $[13,66,78]$. To predict the risk of gastric cancer development and diagnose atrophic gastritis, new serologic testing for a combination of pepsinogen I and II and gastrin and HP antibodies has yielded satisfactory results over the last decades. Also old age, alcohol, and smoking habits are risk factors for gastric cancer. A prevention of gastric cancer can be obtained by eradication of HP, the success of which depends on the degree of preneoplastic changes (gastric atrophy and intestinal metaplasia) at the time of eradication.

Virulence determinants of HP may be connected to gastric carcinogenesis; the use of genomewide germline analyses might offer the chance to identify high-risk groups of gastric cancer [79].

\section{Conclusions}

Many different factors play a role in the development of HP infection, including geography, ethnicity, age, and socioeconomic elements. The efficacy of various available treatment strategies varies significantly within different regions. A progressive decline in infection rates has been secondary to the improvements in sanitation as well as to the use of combination anti-HP regimens over the past decades. The gradual increase in failure of HP eradication treatments is mainly secondary to antimicrobial resistance, in particular to clarithromycin.
Quadruple therapy (PPI + CAM + AMPC and/or MNZ \pm Bismuth) and sequential therapy (PPI + AMPC for 5 days, then PPI + CAM + MNZ for other 5 days) are efficacious alternatives to standard triple therapy for both adults and children. The main current effort should be to maintain the eradication rate of $\mathrm{HP}$ above $85 \%$ and to prevent any increase in antimicrobial resistance in the general population. The possibility of a tailored therapy will be a chance in the next future to optimize the most effective eradication regimen within the various geographical areas.

\section{References}

[1] G. Sachs, D. R. Scott, and Y. Wen, "Gastric infection by Helicobacter pylori," Current Gastroenterology Reports, vol. 13, no. 6, pp. 540-546, 2011.

[2] S. Suerbaum and P. Michetti, "Helicobacter pylori infection," The New England Journal of Medicine, vol. 347, no. 15, pp. 1175-1186, 2002.

[3] C. Chiesa, L. Pacifico, C. Anania, E. Poggiogalle, F. Chiarelli, and J. F. Osborn, "Helicobacter pylori therapy in children: overview and challenges," International Journal of Immunopathology and Pharmacology, vol. 23, no. 2, pp. 405-416, 2010.

[4] N. Muñoz, "Is Helicobacter pylori a cause of gastric cancer? An appraisal of the seroepidemiological evidence," Cancer Epidemiology Biomarkers and Prevention, vol. 3, no. 5, pp. 445451, 1994.

[5] H. Suzuki, F. Franceschi, T. Nishizawa, and A. Gasbarrini, "Extragastric manifestations of Helicobacter pylori infection," Helicobacter, vol. 16, supplement 1, pp. 65-69, 2011.

[6] K. E. L. McColl, "Helicobacter pylori infection," The New England Journal of Medicine, vol. 362, no. 17, pp. 1597-1604, 2010.

[7] J. B. Watson, S. F. Moss, and H. Will, "Pylori stagger under the weight of this LOAD? A novel but expensive eradication regimen," The American Journal of Gastroenterology, vol. 106, no. 11, pp. 1976-1977, 2011.

[8] F. Parente, C. Cucino, and G. Bianchi Porro, "Treatment options for patients with Helicobacter pylori infection resistant to one or more eradication attempts," Digestive and Liver Disease, vol. 35, no. 8, pp. 523-528, 2003.

[9] K. H. Hung, B. S. Sheu, W. L. Chang, H. M. Wu, C. C. Liu, and J. J. Wu, "Prevalence of primary fluoroquinolone resistance among clinical isolates of Helicobacter pylori at a University Hospital in Southern Taiwan," Helicobacter, vol. 14, no. 1, pp. 61-65, 2009.

[10] P. Malfertheiner, F. Megraud, C. O’Morain et al., "Current concepts in the management of Helicobacter pylori infection: the Maastricht III Consensus Report," Gut, vol. 56, no. 6, pp. 772-781, 2007.

[11] N. Broutet, A. Marais, H. Lamouliatte et al., "cagA status and eradication treatment outcome of anti-Helicobacter pylori triple therapies in patients with nonulcer dyspepsia," Journal of Clinical Microbiology, vol. 39, no. 4, pp. 1319-1322, 2001.

[12] G. Treiber, J. Wittig, S. Ammon, S. Walker, L. J. van Doorn, and U. Klotz, "Clinical outcome and influencing factors of a new short-term quadruple therapy for Helicobacter pylori eradication: a Randomized controlled trial (MACLOR study)," Archives of Internal Medicine, vol. 162, no. 2, pp. 153-160, 2002. 
[13] G. Guariso, D. Basso, C. F. Bortoluzzi et al., "GastroPanel: evaluation of the usefulness in the diagnosis of gastroduodenal mucosal alterations in children," Clinica Chimica Acta, vol. 402, no. 1-2, pp. 54-60, 2009.

[14] L. M. Brown, "Helicobacter pylori: epidemiology and routes of transmission," Epidemiologic Reviews, vol. 22, no. 2, pp. 283297, 2000.

[15] R. H. Hunt, S. D. Xiao, F. Megraud et al., "World gastroenterology organisation global guideline: Helicobacter pylori in developing countries," Journal of Clinical Gastroenterology, vol. 20, no. 3, pp. 299-304, 2011.

[16] A. O’Connor, J. P. Gisbert, D. McNamara, and C. O’Morain, “Treatment of Helicobacter pylori infection 2011," Helicobacter, vol. 16, supplement 1, pp. 53-58, 2011.

[17] P. Malfertheiner, F. Bazzoli, J. C. Delchier et al., "Helicobacter pylori eradication with a capsule containing bismuth subcitrate potassium, metronidazole, and tetracycline given with omeprazole versus clarithromycin-based triple therapy: a randomised, open-label, non-inferiority, phase 3 trial," The Lancet, vol. 377, no. 9769, pp. 905-913, 2011.

[18] L. Fischbach and E. L. Evans, "Meta-analysis: the effect of antibiotic resistance status on the efficacy of triple and quadruple first-line therapies for Helicobacter pylori," Alimentary Pharmacology and Therapeutics, vol. 26, no. 3, pp. 343357, 2007.

[19] L. Perez Aldana, M. Kato, S. Nakagawa et al., "The relationship between consumption of antimicrobial agents and the prevalence of primary Helicobacter pylori resistance," Helicobacter, vol. 7, no. 5, pp. 306-309, 2002.

[20] S. Padol, Y. Yuan, M. Thabane, I. T. Padol, and R. H. Hunt, "The effect of CYP2C19 polymorphisms on H. pylori eradication rate in dual and triple first-line PPI therapies: a meta-analysis," American Journal of Gastroenterology, vol. 101, no. 7, pp. 1467-1475, 2006.

[21] V. De Francesco, F. Giorgio, C. Hassan et al., "Worldwide H. pylori antibiotic resistance: a systematic review," Journal of Gastrointestinal and Liver Diseases, vol. 19, no. 4, pp. 409-414, 2010.

[22] S. K. Chuah, F. W. Tsay, P. I. Hsu, and D. C. Wu, "A new look at anti-Helicobacter pylori therapy," World Journal of Gastroenterology, vol. 17, no. 35, pp. 3971-3975, 2011.

[23] J. P. Gisbert, R. Pajares, and J. M. Pajares, "Evolution of Helicobacter pylori therapy from a meta-analytical perspective," Helicobacter, vol. 12, supplement 2, pp. 50-58, 2007.

[24] R. M. Genta and D. Y. Graham, "Comparison of biopsy sites for the histopathologic diagnosis of Helicobacter pylori: a topographic study of H. pylori density and distribution," Gastrointestinal Endoscopy, vol. 40, no. 3, pp. 342-345, 1994.

[25] F. Megraud, "Helicobacter pylori and antibiotic resistance," Gut, vol. 56, no. 11, p. 1502, 2007.

[26] E. Rimbara, L. A. Fischbach, and D. Y. Graham, "Optimal therapy for Helicobacter pylori infections," Nature Reviews Gastroenterology and Hepatology, vol. 8, no. 2, pp. 79-88, 2011.

[27] M. Selgrad and P. Malfertheiner, "Treatment of Helicobacter pylori," Current Opinion in Gastroenterology, vol. 27, no. 6, pp. 565-570, 2011.

[28] T. Kamada, K. Haruma, K. Komoto et al., "Effect of smoking and histological gastritis severity on the rate of $\mathrm{H}$. pylori eradication with omeprazole, amoxicillin, and clarithromycin," Helicobacter, vol. 4, no. 3, pp. 204-210, 1999.

[29] M. Abdullahi, B. Annibale, D. Capoccia et al., "The eradication of Helicobacter pylori is affected by body mass index (BMI)," Obesity Surgery, vol. 18, no. 11, pp. 1450-1454, 2008.
[30] J. P. A. O'Connor, I. Taneike, and C. O’Morain, "Improving compliance with Helicobacter pylori eradication therapy: when and how?" Therapeutic Advances in Gastroenterology, vol. 2, no. 5, pp. 273-279, 2009.

[31] N. Vakil, "H. pylori treatment: new wine in old bottles," American Journal of Gastroenterology, vol. 104, no. 1, pp. 2630, 2009.

[32] M. Asaka, M. Kato, S. I. Takahashi et al., "Guidelines for the management of Helicobacter pylori infection in Japan: 2009 revised edition," Helicobacter, vol. 15, no. 1, pp. 1-20, 2010.

[33] J. P. Gisbert and X. Calvet, "Review article: non-bismuth quadruple (concomitant) therapy for eradication of Helicobater pylori," Alimentary Pharmacology and Therapeutics, vol. 2011, no. 34, pp. 604-617, 2011.

[34] Y. Wenzhen, L. Yumin, G. Quanlin et al., "Is antimicrobial susceptibility testing necessary before first-line treatment for Helicobacter pylori infection? Meta-analysis of randomized controlled trials," Internal Medicine, vol. 49, no. 12, pp. 11031109, 2010.

[35] L. G. Coelho, R. Leon-Barua, and E. M. Quigley, "LatinAmerican Consensus Conference on Helicobacter pylori infection. Latin-American National Gastroenterological Societies affiliated with the Inter-American Association of Gastroenterology (AIGE)," The American Journal of Gastroenterology, vol. 95, no. 10, pp. 2688-2691, 2000.

[36] T. Furuta and D. Y. Graham, "Pharmacologic aspects of eradication therapy for Helicobacter pylori infection," Gastroenterology Clinics of North America, vol. 39, no. 3, pp. 465480, 2010.

[37] K. L. Chan, H. Zhou, D. K. K. Ng, and P. K. H. Tam, "A prospective study of a one-week nonbismuth quadruple therapy for childhood Helicobacter pylori infection," Journal of Pediatric Surgery, vol. 36, no. 7, pp. 1008-1011, 2001.

[38] P. M. Neville, S. Everett, H. Langworthy et al., "The optimal antibiotic combination in a 5-day Helicobacter pylori eradication regimen," Alimentary Pharmacology and Therapeutics, vol. 13, no. 4, pp. 497-501, 1999.

[39] T. Furuta, Y. Sagehashi, N. Shirai et al., "Influence of CYP2C19 polymorphism and Helicobacter pylori genotype determined from gastric tissue samples on response to triple therapy for $\mathrm{H}$ pylori infection," Clinical Gastroenterology and Hepatology, vol. 3, no. 6, pp. 564-573, 2005.

[40] W. D. Chey and B. C. Y. Wong, "American College of Gastroenterology guideline on the management of Helicobacter pylori infection," American Journal of Gastroenterology, vol. 102, no. 8, pp. 1808-1825, 2007.

[41] L. G. Coelho, R. Leon-Barua, and E. M. M. Quigley, "LatinAmerican consensus conference on Helicobacter pylori infection," American Journal of Gastroenterology, vol. 95, no. 10, pp. 2688-2691, 2000.

[42] D. Y. Graham and L. Fischbach, "Helicobacter pylori treatment in the era of increasing antibiotic resistance," Gut, vol. 59, no. 8, pp. 1143-1153, 2010.

[43] L. Laine, M. B. Fennerty, M. Osato et al., "Esomeprazolebased Helicobacter pylori eradication therapy and the effect of antibiotic resistance: results of three US multicenter, doubleblind trials," American Journal of Gastroenterology, vol. 95, no. 12, pp. 3393-3398, 2000.

[44] N. Vakil, F. Lanza, H. Schwartz, and J. Barth, "Sevenday therapy for Helicobacter pylori in the United States," Alimentary Pharmacology and Therapeutics, vol. 20, no. 1, pp. 99-107, 2004.

[45] M. J. R. Janssen, A. H. A. M. Van Oijen, A. L. M. Verbeek, J. B. M. J. Jansen, and W. A. De Boer, "A systematic comparison of 
triple therapies for treatment of Helicobacter pylori infection with proton pump inhibitor/ranitidine bismuth citrate plus clarithromycin and either amoxicillin or a nitroimidazole," Alimentary Pharmacology and Therapeutics, vol. 15, no. 5, pp. 613-624, 2001.

[46] N. S. Jafri, C. A. Hornung, and C. W. Howden, "Meta-analysis: sequential therapy appears superior to standard therapy for Helicobacter pylori infection in patients naive to treatment," Annals of Internal Medicine, vol. 148, no. 12, pp. 923-931, 2008.

[47] L. Boyanova and I. Mitov, "Geographic map and evolution of primary Helicobacter pylori resistance to antibacterial agents," Expert Review of Anti-Infective Therapy, vol. 8, no. 1, pp. 5970, 2010.

[48] W. D. Chey and B. C. Y. Wong, "American College of Gastroenterology guideline on the management of Helicobacter pylori infection," American Journal of Gastroenterology, vol. 102, no. 8, pp. 1808-1825, 2007.

[49] S. Miura and R. Hokari, "Seeking an optimal eradication therapy for Helicobacter pylori infection," Journal of Gastroenterology and Hepatology, vol. 27, pp. 1-9, 2012.

[50] E. Gené, X. Calvet, R. Azagra, and J. P. Gisbert, “Triple vs. Quadruple therapy for treating Helicobacter pylori infection: an updated meta-analysis," Alimentary Pharmacology and Therapeutics, vol. 18, no. 5, pp. 543-544, 2003.

[51] M. Hojo, H. Miwa, A. Nagahara, and N. Sato, "Pooled analysis on the efficacy of the second-line treatment regimens for Helicobacter pylori infection," Scandinavian Journal of Gastroenterology, vol. 36, no. 7, pp. 690-700, 2001.

[52] J. P. Gisbert and A. G. McNicholl, "Maintenance of Helicobacter pilori eradication rates with triple therapy over 12 years in a Spanish Hospital," Helicobacter, vol. 17, no. 2, pp. 160-161, 2012.

[53] M. A. Webber and L. J. V. Piddock, "The importance of efflux pumps in bacterial antibiotic resistance," Journal of Antimicrobial Chemotherapy, vol. 51, no. 1, pp. 9-11, 2003.

[54] K. Murakami, T. Fujioka, T. Okimoto, R. Sato, M. Kodama, and M. Nasu, "Drug combinations with amoxycillin reduce selection of clarithromycin resistance during Helicobacter pylori eradication therapy," International Journal of Antimicrobial Agents, vol. 19, no. 1, pp. 67-70, 2002.

[55] D. Vaira, A. Zullo, N. Vakil et al., "Sequential therapy versus standard triple-drug therapy for Helicobacter pylori eradication: a randomized trial," Annals of Internal Medicine, vol. 146, no. 8, pp. 556-563, 2007.

[56] L. Gatta, N. Vakil, G. Leandro, F. Di Mario, and D. Vaira, "Sequential therapy or triple therapy for Helicobacter pylori infection: systematic review and meta-analysis of randomized controlled trials in adults and children," American Journal of Gastroenterology, vol. 104, no. 12, pp. 3069-3079, 2009.

[57] R. Francavilla, E. Lionetti, and L. Cavallo, "Sequential treatment for Helicobacter pylori eradication in children," Gut, vol. 57, no. 8, p. 1178, 2008.

[58] J. L. Tong, Z. H. Ran, J. Shen, and S. D. Xiao, "Sequential therapy vs. Standard triple therapies for Helicobacter pylori infection: a meta-analysis," Journal of Clinical Pharmacy and Therapeutics, vol. 34, no. 1, pp. 41-53, 2009.

[59] R. J. F. Laheij, L. G. M. Van Rossum, J. B. M. J. Jansen, H. Straatman, and A. L. M. Verbeek, "Evaluation of treatment regimens to cure Helicobacter pylori infection-a metaanalysis," Alimentary Pharmacology and Therapeutics, vol. 13, no. 7, pp. 857-864, 1999.

[60] E. R. Greenberg, G. L. Anderson, D. R. Morgan et al., "14-day triple, 5-day concomitant, and 10-day sequential therapies for
Helicobacter pylori infection in seven Latin American sites: a randomised trial," The Lancet, vol. 378, no. 9790, pp. 507-514, 2011.

[61] P. I. Hsu, D. C. Wu, J. Y. Wu, and D. Y. Graham, "Is there a benefit to extending the duration of Helicobacter pylori sequential therapy to 14 days?" Helicobacter, vol. 16, no. 2, pp. 146-152, 2011.

[62] S. Miehlke, C. Kirsch, W. Schneider-Brachert et al., "A prospective, randomized study of quadruple therapy and highdose dual therapy for treatment of Helicobacter pylori resistant to both metronidazole and clarithromycin," Helicobacter, vol. 8, no. 4, pp. 310-319, 2003.

[63] T. A. Attumi and D. Y. Graham, "Increasing the duration of dual amoxicillin plus omeprazole Helicobacter pylori eradication to 6 weeks: a pilot study," Journal of Gastroenterology and Hepatology, vol. 27, pp. 59-61, 2012.

[64] R. J. Saad, P. Schoenfeld, M. K. Hyungjin, and W. D. Chey, "Levofloxacin-based triple therapy versus bismuthbased quadruple therapy for persistent Helicobacter pylori infection: a meta-analysis," American Journal of Gastroenterology, vol. 101, no. 3, pp. 488-496, 2006.

[65] P. Basu, K. Rayapudi, T. Pacana et al., "A randomized study comparing levofloxacin, omeprazole, nitazoxanide, and doxycycline versus triple therapy for the eradication of Helicobacter pylori," The American Journal of Gastroenterology, vol. 106, no. 11, pp. 1970-1975, 2011.

[66] S. Baba, Y. Oishi, Y. Watanabe et al., "Gastric wash-based molecular testing for antibiotic resistance in Helicobacter pylori," Digestion, vol. 84, no. 4, pp. 299-305, 2011.

[67] H. Szajewska, A. Horvath, and A. Piwowarczyk, "Metaanalysis: the effects of Saccharomyces boulardii supplementation on Helicobacter pylori eradication rates and side effects during treatment," Alimentary Pharmacology and Therapeutics, vol. 32, no. 9, pp. 1069-1079, 2010.

[68] R. Francavilla, E. Lionetti, S. P. Castellaneta et al., "Inhibition of Helicobacter pylori infection in humans by Lactobacillus reuteri ATCC 55730 and effect on eradication therapy: a pilot study," Helicobacter, vol. 13, no. 2, pp. 127-134, 2008.

[69] S. Koletzko, N. L. Jones, K. J. Goodman et al., "Evidence-based guidelines from ESPGHAN and NASPGHAN for Helicobacter pylori infection in children," Journal of Pediatric Gastroenterology and Nutrition, vol. 53, no. 2, pp. 230-243, 2011.

[70] A. Alakkari, A. Zullo, and H. J. O’Connor, "Helicobacter pylori and nonmalignant diseases," Helicobacter, vol. 16, supplement 1, pp. 33-37.

[71] A. C. De Vries and E. J. Kuipers, "Helicobacter pylori infection and Nonmalignant Diseases," Helicobacter, vol. 15, supplement 1, pp. 29-33, 2010.

[72] M. Rathbone and B. Rathbone, "Helicobacter pylori and gastric cancer," Recent Results in Cancer Research, vol. 185, pp. 83-97, 2011.

[73] D. Cullen, G. Hawkey, D. Greenwood et al., "Helicobacter pylori and gastroesophageal reflux disease: a CommunityBased Study," Helicobacter, vol. 13, no. 5, pp. 352-360, 2008.

[74] D. Y. Graham, "The changing epidemiology of GERD: geography and Helicobacter pylori," American Journal of Gastroenterology, vol. 98, no. 7, pp. 1462-1470, 2003.

[75] A. S. Raghunath, A. P. S. Hungin, D. Wooff, and S. Childs, "Systematic review: the effect of Helicobacter pylori and its eradication on gastro-oesophageal reflux disease in patients with duodenal ulcers or reflux oesophagitis," Alimentary Pharmacology and Therapeutics, vol. 20, no. 7, pp. 733-744, 2004. 
[76] B. Qian, S. Ma, L. Shang, J. Qian, and G. Zhang, "Effects of Helicobacter pylori eradication on gastroesophageal reflux disease," Helicobacter, vol. 16, no. 4, pp. 255-265, 2011.

[77] M. Rathbone and B. Rathbone, "Helicobacter pylori and gastric cancer," Recent Results in Cancer Research, vol. 185, pp. 83-97, 2011.

[78] M. Selgrad, J. Bornschein, T. Rokkas, and P. Malfertheiner, "Clinical aspects of gastric cancer and Helicobacter pyloriscreening, prevention, and treatment," Helicobacter, vol. 15, supplement 1, pp. 40-45, 2010.

[79] T. Yoshida, H. Ono, A. Kuchiba, N. Saeki, and H. Sakamoto, "Genome-wide germline analyses on cancer susceptibility and GeMDBJ database: gastric cancer as an example," Cancer Science, vol. 101, no. 7, pp. 1582-1589, 2010. 


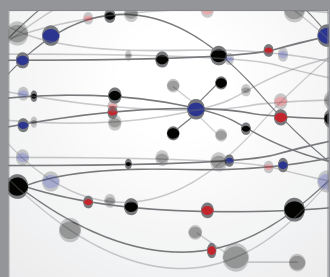

The Scientific World Journal
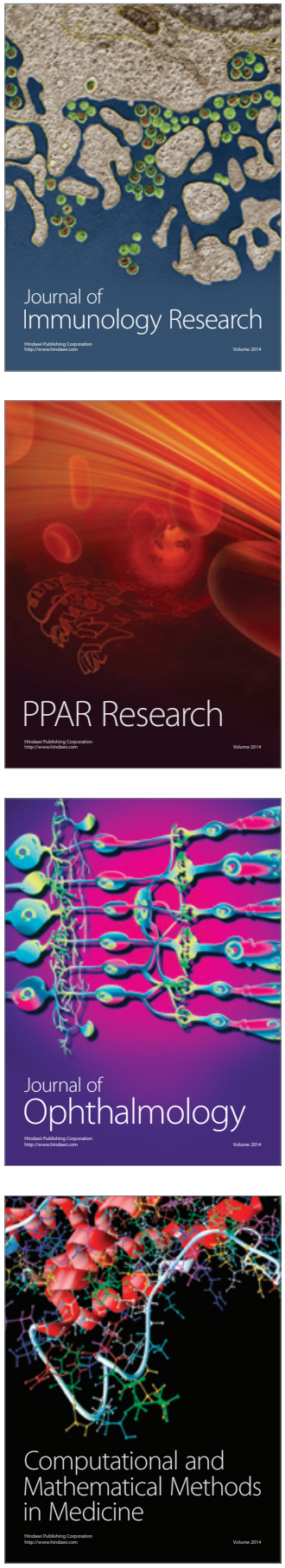

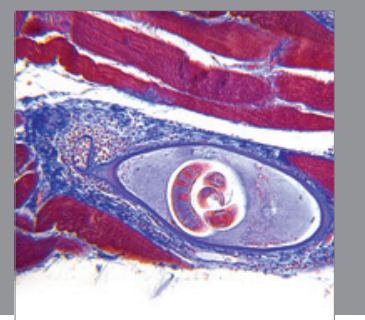

Gastroenterology

Research and Practice
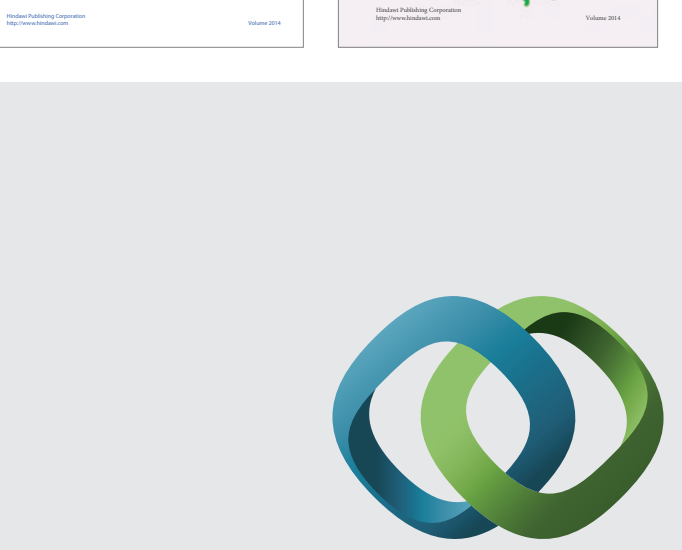

\section{Hindawi}

Submit your manuscripts at

http://www.hindawi.com
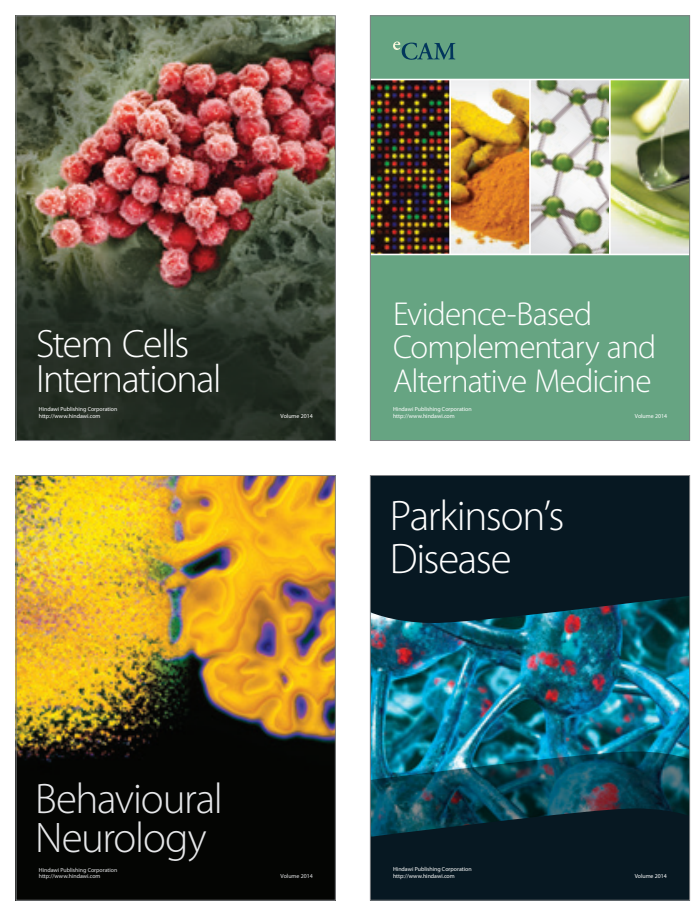

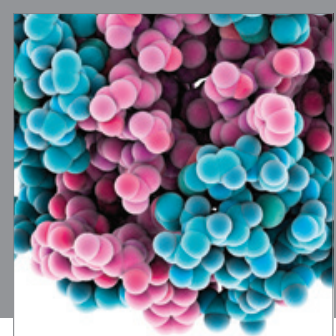

Journal of
Diabetes Research

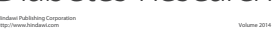

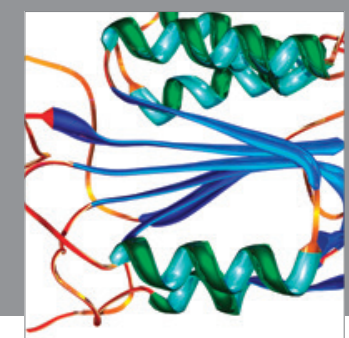

Disease Markers
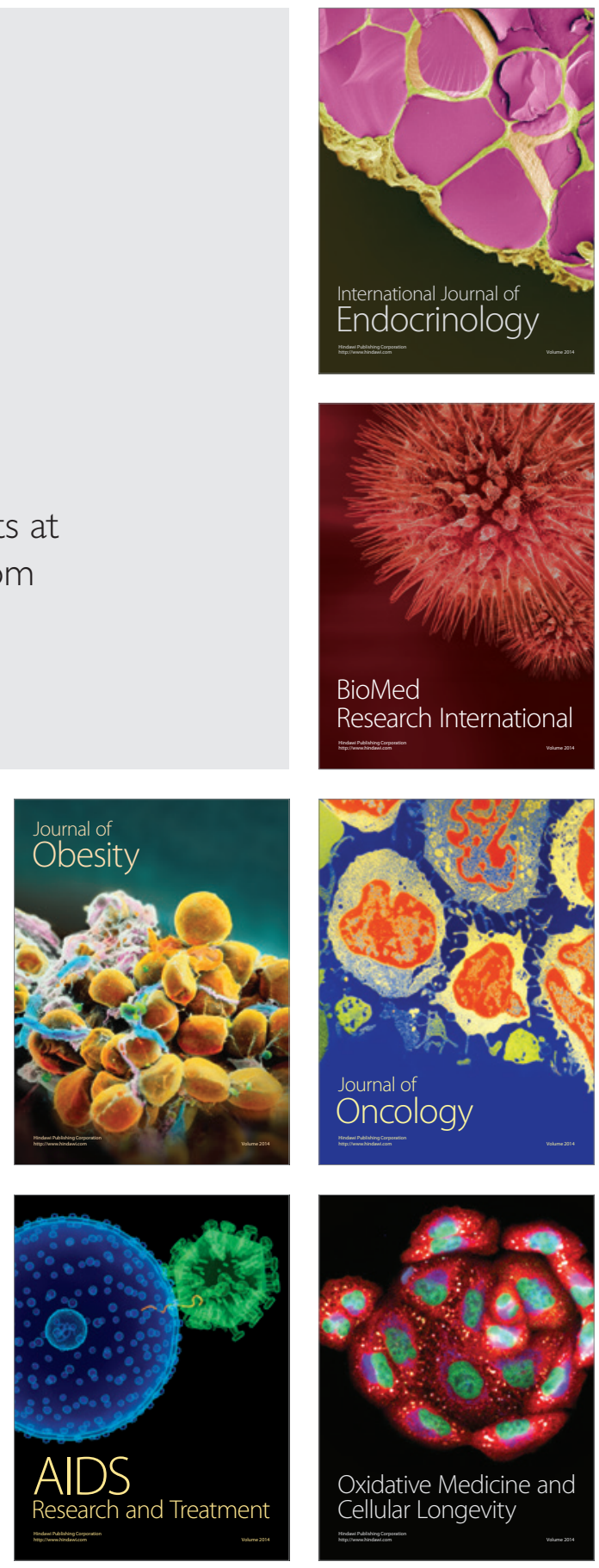